\title{
PERSEPSI KONSUMEN TERHADAP MARKETPLACE TOKOPEDIA DAN SHOPEE DI KECAMATAN CIBINONG KABUPATEN BOGOR
}

\author{
${ }^{1)}$ Dasmansyah Adyas, ${ }^{2)}$ Desy Nur Cahyani \\ ${ }^{1)}$ Dosen Program Studi Manajemen, STIE Dewantara \\ J1. Raya Pemda Bojong Depok Baru III, Karadenan, Cibinong, Bogor, Jawa Barat 16913,Indonesia \\ Email: dasmasnyah.adyas@dewantara.ac.id \\ ${ }^{2)}$ Alumni Program Studi Manajemen, STIE Dewantara \\ Jl. Raya Pemda Bojong Depok Baru III, Karadenan, Cibinong, Bogor, Jawa Barat 16913,Indonesia \\ Email: desyncahyani3@gmail.com
}

\begin{abstract}
This study aims to determine how consumers perceive the Tokopedia and Shopee marketplaces on the dimensions of product, price, promotion, and ease of use, namely in the community in the Cibinong District, Bogor Regency. This research uses descriptive research with a quantitative approach and uses data analysis techniques Weighted Means Score (WMS) by comparing the average value of each variable. Analysis of the assessment of consumer perceptions of the Tokopedia and Shopee markets is measured by a Likert scale using a questionnaire distributed to 150 respondents who have purchased at the Tokopedia and Shopee markets. The results of this study indicate that the product variable (X1) Shopee (with a score of 4.35) is superior to Tokopedia (with a score of 4.01), on the price variable (X2) Shopee (with a score of 4.24) is superior to Tokopedia ( with a score of 3.98), on the promotional variable (X3) Shopee (with a score of 4.38) was superior to Tokopedia (with a score of 4.07), and on the variable using Shopee (X4) (with a score of 4.42) was more superior to Tokopedia (with a score of 4.21).
\end{abstract}

Keywords: Consumer's Perception, Marketplace, Product, Price, Promotion, Tokopedia, Shopee.

\begin{abstract}
ABSTRAK
Penelitian ini bertujuan mengetahui bagaimana persepsi konsumen terhadap marketplace Tokopedia dan Shopee pada dimensi produk, harga, promosi, dan kemudahan penggunaan yaitu pada masyarakat di daerah Kecamatan Cibinong Kabupaten Bogor. Penelitian ini menggunakan jenis penelitian deskriptif dengan pendekatan kuantitatif dan menggunakan teknik analisis data Weighted Means Score (WMS) dengan membandingkan nilai rata-rata dari masing-masing variabel. Penilaian analisa persepsi konsumen terhadap marketplace Tokopedia dan Shopee diukur dengan skala likert dengan menggunakan kuesioner yang disebar pada 150 responden yang pernah membeli di maretplace Tokopedia dan Shopee. Hasil penelitian ini menunjukkan bahwa pada variabel produk (X1) Shopee (dengan skor 4,35) lebih unggul dari Tokopedia (dengan skor 4,01), pada variabel harga (X2) Shopee (dengan skor 4,24) lebih unggul dari Tokopedia (dengan skor 3,98), pada variabel promosi (X3) Shopee (dengan skor 4,38) lebih unggul dari Tokopedia (dengan skor 4,07), dan pada variabel kemudahan penggunaan (X4) Shopee (dengan skor 4,42) lebih unggul dari Tokopedia (dengan skor 4,21).
\end{abstract}

Kata kunci : Persepsi konsumen, Marketplace, Produk, Harga, Promosi, Tokopedia, Shopee.

1. PENDAHULUAN net atau biasa disebut dengan jual-beli

1.1 Latar Belakang

Pada saat ini dunia telah masuk pada era globalisasi, dimana pada era ini ilmu pengetahuan dan teknologi sangat berkembang pesat. Hal tersebut berdampak pula pada perkembangan di bidang perniagaan. Munculnya trend perniagaan berbasis inter- online sangat menarik perhatian masyarakat, karena banyak keuntungan yang didapat dari jual-beli online dalam segi waktu, efektifi-tas, biaya, dan sebagainya. Bergesernya peri-laku konsumen saat ini dari belanja offline menjadi online dikarenakan pertumbuhan 
sektor perdagangan elektronik (e-Commerce) yang positif.

Berbicara tentang e-commerce yang menjadi trend pembelian masa kini tidak luput juga dengan adanya istilah marketplace. Semakin maraknya pertumbuhan $e$ commerce pada saat ini, memaksa masingmasing pihak pengelola marketplace berlomba untuk memberikan pelayanan terbaik bagi konsumen agar mereka tidak kehilangan pelanggan dan mampu menguasai pasar daring.

Menurut iprice.co.id dalam peta $e$ commerce Indonesia, dapat dilihat pada tabel 1 menyebutkan beberapa peringkat marketplace pada quartal 3 di tahun 2019. Dari data tersebut dapat disimpulkan, bahwa berdasarkan jumlah pengunjung Tokopedia berhasil menduduki peringkat pertama, sementara Shopee berhasil menduduki posisi pertama pada peringkat jumlah pengunduhan di playstore. Dua marketplace ini, bisa dibilang menjadi marketplace yang diminati masyarakat Indonesia pada saat ini.

Tabel 1. Jumlah Pengunjung Web Bulanan dan Peringkat Marketplace Berdasarkan Pengunduhan di Playstore

\begin{tabular}{|c|l|c|c|}
\hline $\begin{array}{c}\mathrm{N} \\
\mathrm{o}\end{array}$ & $\begin{array}{c}\text { Marketplac } \\
e\end{array}$ & $\begin{array}{c}\text { Pengunjun } \\
\text { g Web } \\
\text { (Bulanan) }\end{array}$ & $\begin{array}{c}\text { Peringkat } \\
\text { Pengunduha } \\
\mathrm{n} \mathrm{di} \\
\text { Playstore } \\
\text { (Bulanan) }\end{array}$ \\
\hline 1 & Tokopedia & 65.953 .400 & 3 \\
\hline 2 & Shopee & 55.964 .700 & 1 \\
\hline 3 & Bukalapak & 42.874 .100 & 9 \\
\hline 4 & Lazada & 27.995 .900 & 2 \\
\hline 5 & Blibli & 21.395 .600 & 5 \\
\hline
\end{tabular}

Sumber: iprice.co.id (2019)

Salah satu faktor yang mampu mengubah perilaku konsumen sehingga mendorong konsumen melakukan pembelian online adalah faktor persepsi. Persepsi adalah makna yang kita pertalikan ber-dasarkan pengalaman masa lalu, stimuli (rangsangan-rangsangan) yang kita terima melalui lima indra (Stanton dalam Sangadji dan Sopiah, 2013:64). Semakin baik persep-si yang dipersepsikan konsumen terhadap perusahaan, akan mempengaruhi perilaku konsumen untuk melakukan pembelian, bah-kan persepsi konsumen yang tinggi terhadap perusahaan akan mendorong konsumen un-tuk mengulang pembelian dan menciptakan loyalitas pelanggan pada perusahaan.

\subsection{Perumusan Masalah}

Berdasarakan latar belakang masalah dan ruang lingkup masalah di atas, maka perumusan masalah dalam penelitian ini adalah:

1. Bagaimana persepsi konsumen pada dimensi produk terhadap marketplace Tokopedia dan Shopee?

2. Bagaimana persepsi konsumen pada dimensi harga terhadap marketplace Tokopedia dan Shopee?

3. Bagaimana persepsi konsumen pada dimensi promosi terhadap marketplace Tokopedia dan Shopee?

4. Bagaimana persepsi konsumen pada dimensi kemudahan penggunaan terhadap marketplace Tokopedia dan Shopee?

\subsection{Tujuan Penelitian}

Adapun tujuan penelitian ini adalah:

1. Untuk menganalisis persepsi konsumen pada dimensi produk terhadap marketplace Tokopedia dan Shopee.

2. Untuk menganalisis persepsi konsumen pada dimensi harga terhadap marketplace Tokopedia dan Shopee.

3. Untuk menganalisis persepsi konsumen pada dimensi promosi terhadap marketplace Tokopedia dan Shopee.

4. Untuk menganalisis persepsi konsumen pada dimensi kemudahan 
penggunaan terhadap marketplace

Tokopedia dan Shopee.

\section{TINJAUAN PUSTAKA}

\subsection{Persepsi Konsumen}

Persepsi merupakan salah satu faktor internal yang ada pada diri konsumen. Kotler dan Keller (2009:179) mendefinisikan persepsi sebagai proses dimana kita memilih, mengatur, dan menerjemahkan masukan informasi untuk menciptakan gambaran dunia yang berarti. Menurut Sangadji dan Sopiah (2013:64) persepsi adalah suatu proses yang timbul akibat adanya sensasi, dimana sensasi adalah aktivitas merasakan atau penyebab keadaan emosi yang menggembirakan. Sedangkan menurut Stanton dalam Sangadji dan Sopiah (2013:64) persepsi dapat didefinisikan sebagai makna yang kita pertalikan berdasarkan pengalaman masa lalu, stimuli (rangsangan-rangsangan) yang kita terima melalui lima indra.

\subsection{Persepsi Produk}

Persepsi terhadap produk yaitu bagaimana konsumen memandang produk yang akan dibelinya yaitu sesuai dengan selera dan harapannya atau tidak. Produk dan atribut produk adalah stimulus utama yang mempengaruhi afeksi, kognisi, dan perilaku konsumen (Peter dan Olson, 2014:189). Sedangkan produk menurut Stanton dalam Alma $(2018,140)$ ialah Seperangkat atribut baik berwujud maupun tidak berwujud, termasuk didalamnya masalah warna, harga, nama baik pabrik, nama baik toko, yang menjual (pengecer), dan pelayan baik pabrik serta pelayanan pengecer, yang diterima oleh pembeli guna memuaskan keinginannya.

\subsection{Persepsi Harga}

Persepsi terhadap harga adalah salah satu faktor yang berpengaruh terhadap keputusan pembelian konsumen, terlebih pada pembelian online. Harga yang ditawarkan marketplace lebih memungkinkan konsumen memilih produk dengan harga yang sesuai dan cara yang efektif dan mudah yaitu hanya memilih produk dengan harga yang tertera di aplikasi berbasis web. Persepsi atas harga menyangkut bagaimana informasi harga dipahami oleh konsumen dan dibuat bermakna bagi mereka (Peter dan Olson, 2014:246). Sementara harga sendiri didefinisikan sebagai nilai suatu barang yang dinyatakan dalam uang (Alma, 2018:171).

\subsection{Persepsi Promosi}

$\begin{array}{rlr}\text { Diantara } & \text { faktor-faktor } \begin{array}{r}\text { yang } \\ \text { menyebabkan }\end{array} \\ \text { perubahan } & \text { perilaku }\end{array}$ konsumen dari pembelian tradisional menjadi pembelian online adalah persepsi konsumen tehadap promosi yang dilancarkan oleh pengusaha. Tidak dapat dipungkiri bahwa promosi yang diberikan marketplace sangat menarik persepsi dan perhatian konsumen karena dinilai sangat menguntungkan dalam segi finansial maupun waktu. Menurut Sangadji dan Sopiah (2013:9) promosi adalah semua jenis kegiatan pemasaran yang ditujukan untuk mendorong permintaan konsumen atas produk yang ditawarkan produsen atau penjulan.

\subsection{Persepsi Kemudahan Penggunaan}

Persepsi kemudahan penggunaan merupakan faktor yang tidak kalah penting dalam penggunaan sebuah teknologi. Kemudahan menurut Kamus Besar Bahasa Indonesia (KBBI) adalah hal (sifat) mudah, keadaan mudah, atau sesuatu yang dapat mempermudah dan memperlancar usaha. Sedangkan kemudahan penggunaan persepsian (perceived ease of use) didefinisikan sebagai sejauh mana seseorang percaya bahwa menggunakan suatu teknologi akan bebas dari usaha (Jogiyanto, 2007:115). Sehingga dapat disimpulkan bahwa kemudahan 
penggunaaan pada teknologi adalah suatu keadaan yang dirasa teknologi tersebut mudah untuk digunakan tanpa ada hambatan yang membuat pengguna nyaman untuk melakukan.

Kemudahan penggunaan ini merupakan awal dari penggunaan teknologi termasuk dalam penggunaan e-commerce. Kemudahan penggunaan juga merupakan kepercayaan (belief) tentang proses pengambilan keputusan. Apabila seseorang merasa percaya teknologi mudah digunakan maka dia akan menggunakannya, dan sebaliknya apabila seseorang tidak percaya teknologi tersebut mudah digunakan maka dia tidak akan menggunakannya.

\subsection{Marketplace}

Marketlace adalah sarana untuk melakukan kegiatan transaksi dan yang mempertemukan penjual serta pembeli di dunia digital berbasis web.

Menurut Turban et all (2018:8): "Electronic market (E-marketplace) is an online location where buyers and sellers conduct commercial transaction such as selling goods, service, or information. Any individual can also open a private market selling products or service online. Electronic market can also match individuals to others or to jobs. They usually are owned by independent owners. Electronic market are connected to sellers and buyers via the internet or to its counterpart within organizations, an intranet. (Pasar elektronik (e-marketplace) adalah lokasi online di mana pembeli dan penjual melakukan transaksi komersial seperti menjual barang, layanan, atau informasi. Setiap individu juga dapat membuka pasar swasta yang menjual produk atau layanan online. Pasar elektronik juga dapat mencocokkan individu dengan orang lain atau pekerjaan. Mereka biasanya dimiliki oleh pemilik independen. Pasar elektronik terhubung ke penjual dan pembeli melalui internet atau ke mitra dalam organisasi, intranet)."

Sementara Kotler dan Amstrong dalam Malau (2017:298) mengatakan "Marketplace adalah bentuk dari emarketing, dimana e-marketing adalah sisi pemasaran dari e-commerce, yang terdiri dari kerja dari perusahaan untuk mengkomunikasikan sesuatu, mempromosikan, dan menjual barang dan jasa melalui internet."

\subsection{Kerangka Pemikiran}

Berikut kerangka pemikiran dalam penelitian ini :

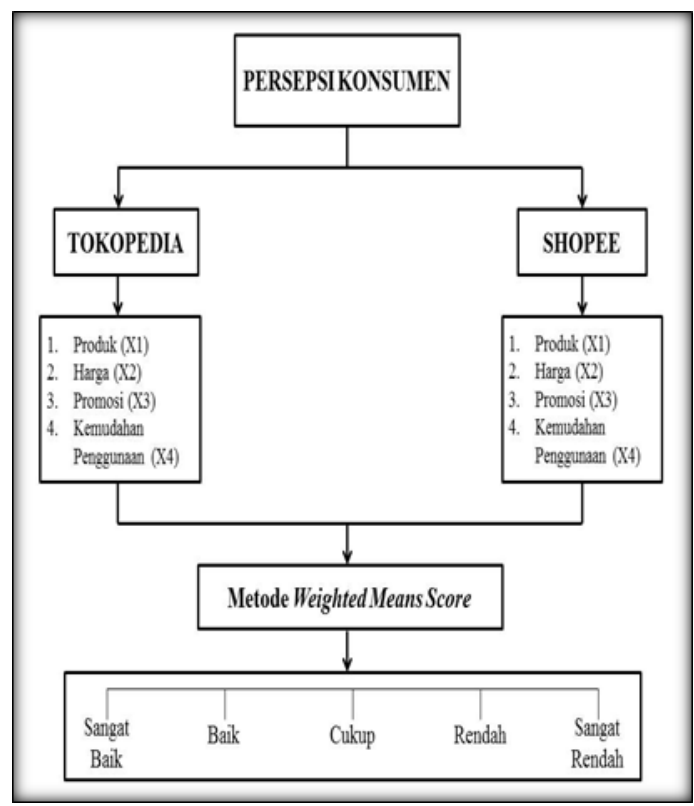

Gambar 1. Kerangka Pemikiran

\section{METODE PENELITIAN}

\subsection{Jenis Penelitian}

Metode penelitian ini menggunakan jenis deskriptif dengan pendekatan kuantitatif yaitu jenis penelitian yang bertujuan untuk menjelaskan atau mendeskripsikan yang berkenaan dengan pernyataan terhadap satu variabel atau lebih, dengan menggunakan instrumen penelitian dan analisis data yang bersifat kuantitatif statistik. 


\subsection{Variabel Penelitian}

Variabel penelitian menurut Sugiyono (2017:39) adalah suatu atribut atau sifat atau nilai dari orang, obyek, atau kegiatan yang mempunyai variasi tertentu yang ditetapkan oleh peneliti untuk dipelajari dan kemudian ditarik kesimpulannya. Variabel yang digunakan dalam penelitian ini adalah variabel bebas (independent), yaitu variabel yang mempengaruhi variabel terikat. Variabel bebas pada penelitian ini adalah persepsi produk (X1), perepsi harga (X2), persepsi promosi (X3), dan persepsi kemudahan penggunaan $(\mathrm{X} 4)$.

\subsection{Lokasi dan Waktu}

Lokasi yang digunakan dalam penelitian ini adalah daerah Kecamatan Cibinong Kabupaten Bogor. Penelitian ini dilakukan selama 5 bulan yakni dimulai dari bulan Agustus 2019 hingga Desember 2019.

\subsection{Objek Penelitian}

Objek penelitian adalah sifat dari keadaan suatu benda, orang, atau keadaan, yang menjadi pusat perhatian atau sasaran penelitian. Adapun objek penelitian ini adalah konsumen Tokopedia dan Shopee di daerah Kecamatan Cibinong Kabupaten Bogor yang pernah melakukan pembelian pada marketplace Tokopedia dan Shopee.

\subsection{Populasi dan Sampel}

Populasi menurut Sugiyono (2017:80) adalah wilayah generalisasi yang terdiri atas objek atau subjek yang mempunyai kualitas dan karakeristik tertentu yang ditetapkan oleh peneliti untuk dipelajari dan kemudian ditarik kesimpulannya. Dalam penelitian ini yang menjadi populasi adalah konsumen di daerah Kecamatan Cibinong KabupatenBogor yang pernah membeli pada marketplace Tokopedia dan Shopee di daerah Kecamatan Cibinong Kabupaten Bogor yang jumlah populasinya tidak diketahui secara pasti jumlah populasinya.
Sugiyono (2017:81) sampel adalah bagian dari jumlah dan karakteristik yang dimiliki oleh populasi. Dalam penarikan jumlah ukuran sampel, apabila populasinya tidak diketahui secara pasti jumlahnya maka digunakan rumus sesuai dengan teori Malhotra (2006:291) paling sedikit harus empat atau lima kali dari jumlah item pertanyaan. Jadi jumlah sampel yang diambil dalam penelitian ini adalah 150 orang (30 item pertanyaan X $5=150$ ), yaitu 150 orang untuk menduga populasi.

Pengambilan sampel dilakukan dengan menggunakan metode nonprobability sampling yaitu teknik pengambilan sampel yang tidak memberikan peluang atau kesempatan sama bagi setiap unsur (anggota) populasi untuk dipilih menjadi anggota sampel (Sugiyono, 2017:84).

Dalam penarikan jumlah ukuran sampel, teknik pengambilan sampel yang digunakan dalam penelitian ini adalah secara quota sampling, yaitu teknik untuk menentukan sampel dari populasi yang mempunyai ciri-ciri tertentu sampai jumlah (kuota) yang diinginkan (Sugiyono, 2017:85). Ciri yang dimaksud adalah konsumen yang pernah membeli pada marketplace yaitu Tokopedia dan Shopee di Kecamatan Cibinong.

\subsection{Teknik Analisis Data}

Teknik analisis data kuantitatif adalah bentuk analisa yang menggunakan angka angka dan perhitungan dengan metode statistik untuk menguji kebenaran hipotesis penelitian yang telah diajukan sebelumnya. Input data dilakukan berupa tabulasi data melalui software Excel 2010 yang selanjutnya dilakukan pengolahan data dengan menggunakan alat bantu aplikasi software SPSS 22.0 for Windows.

\subsubsection{Uji Validitas}

Uji validitas menurut Priyatno (2014:51) merupakan instrumen data untuk 
mengetahui seberapa cermat suatu item dalam mengukur apa yang ingin diukur.

Pengujian validitas penelitian ini dilakukan dengan uji korelasi Pearson. Syarat penerimaan adalah sebagai berikut :

1. Jika nilai koefisien korelasi ( $\mathrm{r}$ hitung) $<\mathrm{r}$ table, maka item tidak valid.

2. Jika nilai koefisien korelasi ( $\mathrm{r}$ hitung) $>\mathrm{r}$ table, maka item kuesioner valid.

\subsubsection{Uji Reliabilitas}

Uji reliabilitas digunakan untuk mengetahui keajegan atau konsistensi alat ukur yang biasanya menggunakan kuesioner (Priyatno, 2014:64).

Kriteria penilaian uji reliabilitas, sebagai berikut :

a. Apabila hasil koefisien cronbach alpha lebih besar (>) dari taraf signifikansi $60 \%$ atau 0,6 maka kuesioner tersebut reliabel.

b. Apabila hasil koefisien cronbach alpha lebih kecil $(<)$ dari taraf signifikansi $60 \%$ atau 0,6 maka kuesioner tersebut tidak reliabel.

\subsubsection{Uji Weighted Means Score (WMS)}

Teknik ini digunakan untuk mendapatkan kecenderungan skor yang diberikan oleh responden pada setiap item pertanyaan sesuai dengan kriteria atau tolak ukur yang digunakan. Menurut Sugiyono (2003:204) perhitungan rumus dari Weighted Means Score (WMS) adalah sebagai berikut:

$$
\bar{X}=\frac{\Sigma X}{n}
$$

Keterangan:

$\bar{X}=$ Rata-rata Skor Responden

$\Sigma \mathrm{X}=$ Jumlah Skor Dari Jawaban

Responden

$\mathrm{n}=$ Jumlah Responden

\section{HASIL DAN PEMBAHASAN}

\subsection{Gambaran Umum Tokopedia}

Tokopedia didirikan pada 17 Agustus 2009, William Tanuwijaya dan Leontinus Alpha Edison meluncurkan Tokopedia dengan misi pemerataan ekonomi secara digital. Dalam 10 tahun terakhir, Tokopedia mendorong pemerataan ekonomi digital dengan memotivasi masyarakat Indonesia untuk mulai berjualan secara online. Inisiatif ini dilakukan dengan membangun platform yang memungkinkan setiap orang dapat memulai dan menemukan apa pun, di mana pun.

Untuk dekade berikutnya, Tokopedia akan fokus pada upaya mengembangkan Super Ecosystem yang memungkinkan setiap orang dapat berkontribusi dan memberikan nilai tambah bagi satu sama lain serta tumbuh bersama. Tokopedia telah membangun jembatan dengan banyak mitra, termasuk mitra logistik dan pembayaran, dan Tokopedia masih terus berupaya membangun jaringan yang lebih kuat.

Tokopedia tumbuh secara signifikan selama beberapa tahun kebelakang, berikut penjelasan pada tabel di bawah ini :

Tabel 2. Pertumbuhan Tokopedia dari Tahun ke Tahun

\begin{tabular}{|l|l|}
\hline Tahun & \multicolumn{1}{|c|}{ Pencapaian } \\
\hline 2009 & $\begin{array}{l}\text { Tokopedia memulai bisnis } \\
\text { C2C marketplace }\end{array}$ \\
\hline 2014 & $\begin{array}{l}\text { Menjadi perusahaan } \\
\text { Indonesia pertama di } \\
\text { portofolio Softbank dan } \\
\text { Sequoia }\end{array}$ \\
\hline 2015 & $\begin{array}{l}\text { Memelopori instant } \\
\text { delivery dengan } \\
\text { perusahaan transportasi } \\
\text { online }\end{array}$ \\
\hline 2016 & $\begin{array}{l}\text { Mulai memasuki bisnis } \\
\text { Produk Digital dan } \\
\text { Fintech }\end{array}$ \\
\hline 2017 & Mendapatkan pendanaan \\
\hline
\end{tabular}




\begin{tabular}{|l|l|}
\hline \hline & \$1,1 dari Alibaba Group \\
\hline 2018 & $\begin{array}{l}\text { Putaran pendanaan baru } \\
\text { sebesar \$ 1,1 miliar dari } \\
\text { Softbank Vision Fund dan } \\
\text { Alibaba Group }\end{array}$ \\
\hline 2019 & $\begin{array}{l}\text { Mengaukisisi Bridestory } \\
\text { dan Parentstory }\end{array}$ \\
\hline
\end{tabular}

Sumber: www.tokopedia.com

\subsubsection{Bisnis pada Marketplace Tokopedia}

Marketplace Tokopedia menyediakan pilihan produk paling beragam di Indonesia. Tokopedia telah bekerjasama dengan lebih dari 6,6 juta penjual, berbagai toko resmi dan mitra logistik serta pembayaran untuk memberikan pengalaman terbaik bagi pelanggan. Di marketplace Tokopedia, perekonomian Indonesia bergerak di level tinggi yaitu $>1 \%$ dari total perekonomian Indonesia (dengan > 200 Juta Produk, dan > 6,6 Juta penjual).

Jenis kebutuhan sehari-hari yang dapat ditemui pada marketplace Tokopedia diantaranya:

1. Fashion

2. Ibu \& Anak

3. Perawatan Kecantikan

4. Elektronik

5. Makanan \& Kesehatan

6. Otomotif

7. Hobi

8. Rumah Tangga

9. Handphone

Bisnis Lainnya yang dapat pelanggan temui adalah:

1. Teknologi Finansial \& Pembayaran

Penjual ataupun pengguna, layanan teknologi finansial Tokopedia akan memberi pelanggan akses permodalan, solusi investasi terjangkau, dan berbagai opsi pembayaran. Dengan membuat layanan keuangan yang lebih mudah diakses oleh semua orang,
Tokopedia memungkinkan adanya inklusi keuangan di Indonesia.

2. New Retail

Aplikasi Mitra Tokopedia menjembatani kesenjangan antara online dan offline. Mitra Tokopedia menambah nilai ke toko fisik tradisional melalui perluasan jangkauan pelanggan online dan mengekspos penjual ke lebih banyak pilihan pemasok dengan harga cerdas.

3. Logistik \& Fulfillment

Pengiriman menjadi mudah dengan sistem logistik dan fulfillment yang terintegrasi. Pelanggan dapat memilih waktu kedatangan paket yang akan diakomodasi oleh mitra Tokopedia sementara penjual dapat menyimpan produk mereka di gudang pintar Tokopedia yang berlokasi di seluruh Indonesia.

\subsection{Gambaran Umum Shopee}

Shopee adalah platform e-commerce terkemuka di Asia Tenggara dan Taiwan. Platform ini dirancang khusus untuk kawasan ini, dengan memberikan pengalaman belanja online yang mudah, aman, dan cepat kepada pelanggan melalui pembayaran dan dukungan pemenuhan yang kuat.

Shopee percaya belanja online harus dapat diakses, mudah dan menyenangkan. Ini adalah visi yang diinginkan Shopee untuk disampaikan di platform, setiap hari. Shopee percaya pada kekuatan transformatif teknologi dan tujuannya adalah ingin mengubah dunia menjadi lebih baik dengan menyediakan platform untuk menghubungkan pembeli dan penjual dalam satu komunitas.

Shopee sendiri dipimpin oleh Chris Feng. Chris Feng adalah salah satu mantan pegiat Rocket Internet yang pernah mengepalai Zalora dan Lazada. Shopee pertamakali diluncurkan di Singapura pada tahun 2015, sebagai pasar mobile-sentris 
sosial pertama dimana pengguna dapat menjelajahi, berbelanja, dan menjual kapan saja. Terintegrasi dengan dukungan logistik dan pembayaran yang bertujuan untuk membuat belanja online mudah dan aman bagi penjual dan pembeli.

Untuk lebih jelasnya dapat dilihat pada tabel 3 pertumbuhan Shopee dari tahun ke tahun dibawah ini:

Tabel 3. Pertumbuhan Shopee dari Tahun ke Tahun

\begin{tabular}{|l|l|}
\hline Tahun & \multicolumn{1}{|c|}{ Pencapaian } \\
\hline 2015 & Shopee diluncurkan di \\
& Singapura, Indonesia, \\
& Malaysia, Thailand, Taiwan, \\
& Vietnam, dan Filipina. Pada \\
& Desember 2015, Universitas \\
& Shopee mengadakan sesi \\
& Shopee University \\
& pertamanya di Taiwan. Hari \\
& ini, sekitar 70 ribu penjual di \\
& semua pasar telah mendapat \\
& manfaat dari sesi ini. \\
\hline 2017 & Juni 2017, Shopee Mall \\
& diluncurkan di Taiwan dan \\
& memperkenalkan Shopee \\
& Mall di seluruh wilayah \\
& kami sekarang memiliki \\
& lebih dari 11.000 penjual di \\
& 7 pasar. \\
\hline 2018 & $\begin{array}{l}\text { Pada tahun 2018, Nilai } \\
\text { Merchandise Kotor (GMV) } \\
\text { Shopee mencapai US \$ 10 } \\
\text { miliar dengan lebih dari 600 } \\
\text { juta transaksi di platform } \\
\text { ini.Mei 2018, Shopee } \\
\text { meluncurkan Super Brand } \\
\text { Day pertama kami di } \\
\text { Indonesia dengan P\&G } \\
\text { sebagai mitranya. Sejak itu, } \\
\text { Shopee telah } \\
\text { menyelenggara-kan 70 } \\
\text { Super Brand Days di seluruh } \\
\text { wilayah. Pada No-vember } \\
\text { 2018, Shopee }\end{array}$ \\
\hline
\end{tabular}

\begin{tabular}{|l|l|}
\hline & $\begin{array}{l}\text { mengumumkan brand } \\
\text { ambassador regionalnya } \\
\text { yang pertama, } \\
\text { BLACKPINK. }\end{array}$ \\
\hline
\end{tabular}

Sumber: careers.shopee.co.id

\subsubsection{Bisnis pada Marketplace Shopee}

Shopee pertama kali dimulai sebagai pasar pelanggan untuk pelanggan $(\mathrm{C} 2 \mathrm{C})$ tetapi telah beralih ke model hibrid $\mathrm{C} 2 \mathrm{C}$ dan Bisnis untuk Pelanggan (B2C) semenjak meluncurkan Shopee Mall yang merupakan platform toko daring untuk distribusi brand ternama. Bisnis yang ada pada Shopee diantaranya:

1. Pasar Daring

Shopee Indonesia sebagai sarana jual beli daring yang menyediakan berbagai produk untuk menunjang aktivitas sehari-hari yang mencakup fashion, gadget, alat kosmetik, alat elektronik, hobi dan koleksi, fotografi, perlengkapan olahraga, otomotif, vitamin dan suplemen, perlengkapan rumah, makanan dan minuman, souvenir dan pesta, hingga voucher belanja.

2. Investasi

Sebagai anak perusahaan dari SEA Group, Shopee Indonesia mendapatkan dukungan finansial penuh dari SEA Group. Untuk regional Indonesia sendiri, pada saat peluncurannya, Shopee Indonesia mendapatkan dana dari SEA Group dan beberapa modal ventura, seperti Farallon Capital Management, Hillhouse Capital, GDP Venture, JG Summit Holdings Inc untuk melakukan penetrasi pada online market di Indonesia.

3. Sistem pembayaran

Shopee menyediakan berbagai sistem pembayaran untuk pembayaran pulsa, paket data, tagihan BPJS, PLN, TELKOM, PDAM, TV Kabel, dan 
pembayaran tiket kereta api, pesawat, atau bus.

4. Koin, Games, dan Quiz Shopee.

\subsection{Uji Validitas}

Dalam pengujian validitas ini, peneliti menggunakan metode Korelasi Pearson. Teknik uji validitas item dengan Korelasi Pearson dilakukan dengan cara mengorelasikan skor item dengan skor totalnya. Skor total adalah penjumlahan seluruh item pada satu variabel. Kemudian pengujian dilakukan dengan kriteria menggunakan $\mathrm{r}$ tabel $=0,161$ pada tingkat signifikansi 0,05 dengan uji 2 sisi. Apabila $r$ hitung $\geq \mathrm{r}$ tabel maka item dapat dinyatakan valid, jika $r$ hitung < $r$ tabel maka item dapat dinyatakan tidak valid.

Tabel 4. Hasil Uji Validitas Variabel Produk Tokpedia

\begin{tabular}{|c|l|c|c|c|}
\hline No $_{0}$ & Pernyataan & r Hitung & r Tabel & Keterangan \\
\hline 1. & Ketersediaan & 0,892 & 0,161 & Valid \\
\hline 2. & Keragaman & 0,892 & 0,161 & Valid \\
\hline 3. & Kualitas Baik & 0,827 & 0,161 & Valid \\
\hline
\end{tabular}

Sumber: Data primer yang diolah, 2019

Berdasarkan tabel di atas menunjukkan seluruh instrumen valid untuk digunakan sebagai instrumen atau pernyataan untuk mengukur variabel produk yang diteliti pada marketplace Tokopedia.

Tabel 5. Hasil Uji Validitas Variabel Produk Shopee

\begin{tabular}{|c|l|c|c|c|}
\hline No. & Pernyataan & r Hitung & r Tabel & Keterangan \\
\hline 1. & Ketersediaan & 0,887 & 0,161 & Valid \\
\hline 2. & Keragaman & 0,843 & 0,161 & Valid \\
\hline 3. & Kualitas Baik & 0,771 & 0,161 & Valid \\
\hline
\end{tabular}

Sumber: Data primer yang diolah, 2019

Berdasarkan tabel di atas menunjukkan seluruh instrumen valid untuk digunakan sebagai instrumen atau pernyataan untuk mengukur variabel produk yang diteliti pada marketplace Shopee.

Tabel 6. Hasil Uji Validitas Variabel Harga Tokopedia

\begin{tabular}{|c|l|c|c|c|}
\hline No. & Pernyataan & r Hitung & r Tabel & Keterangan \\
\hline 1. & Terjangkau & 0,852 & 0,161 & Valid \\
\hline 2. & $\begin{array}{l}\text { Harga Sesuai } \\
\text { Kualitas }\end{array}$ & 0,882 & 0,161 & Valid \\
\hline 3. & $\begin{array}{l}\text { Harga Sesuai } \\
\text { Manfaat }\end{array}$ & 0,878 & 0,161 & Valid \\
\hline
\end{tabular}

Sumber: Data primer yang diolah, 2019

Berdasarkan tabel di atas menunjukkan seluruh instrumen valid untuk digunakan sebagai instrumen atau pernyataan untuk mengukur variabel harga yang diteliti pada marketplace Tokopedia.

Tabel 7. Hasil Uji Validitas Variabel Harga Shopee

\begin{tabular}{|c|l|c|c|c|}
\hline No. & Pernyataan & r Hitung & r Tabel & Keterangan \\
\hline 1. & Terjangkau & 0,835 & 0,161 & Valid \\
\hline 2. & $\begin{array}{l}\text { Harga Sesuai } \\
\text { Kualitas }\end{array}$ & 0,880 & 0,161 & Valid \\
\hline 3. & $\begin{array}{l}\text { Harga Sesuai } \\
\text { Manfaat }\end{array}$ & 0,886 & 0,161 & Valid \\
\hline
\end{tabular}

Sumber: Data primer yang diolah, 2019

Berdasarkan tabel di atas menunjukkan seluruh instrumen valid untuk digunakan sebagai instrumen atau pernyataan untuk mengukur variabel harga yang diteliti pada marketplace Shopee.

Tabel 8. Hasil Uji Validitas Variabel Promosi Tokopedia

\begin{tabular}{|c|l|c|c|c|}
\hline No. & Pernyataan & r Hitung & r Tabel & Keterangan \\
\hline 1. & Tampilan Fitur & 0,776 & 0,161 & Valid \\
\hline 2. & Promo Harga & 0,844 & 0,161 & Valid \\
\hline 3. & Iklan & 0,815 & 0,161 & Valid \\
\hline 4. & Event & 0,852 & 0,161 & Valid \\
\hline 5. & $\begin{array}{l}\text { Brand } \\
\text { Ambassador }\end{array}$ & 0,830 & 0,161 & Valid \\
\hline
\end{tabular}

Sumber: Data primer yang diolah, 2019 
Berdasarkan tabel di atas menunjukkan seluruh instrumen valid untuk digunakan sebagai instrumen atau pernyataan untuk mengukur variabel promosi yang diteliti pada marketplace Tokopedia.

Tabel 9. Hasil Uji Validitas Variabel Promosi Shopee

\begin{tabular}{|c|l|c|c|c|}
\hline No. & Pernyataan & r Hitung & r Tabel & Keterangan \\
\hline 1. & $\begin{array}{l}\text { Tampilan } \\
\text { Fitur }\end{array}$ & 0,715 & 0,161 & Valid \\
\hline 2. & Promo Harga & 0,697 & 0,161 & Valid \\
\hline 3. & Iklan & 0,840 & 0,161 & Valid \\
\hline 4. & Event & 0,791 & 0,161 & Valid \\
\hline 5. & $\begin{array}{l}\text { Brand } \\
\text { Ambassador }\end{array}$ & 0,754 & 0,161 & Valid \\
\hline
\end{tabular}

Sumber: Data primer yang diolah, 2019

Berdasarkan tabel di atas menunjukkan seluruh instrumen valid untuk digunakan sebagai instrumen atau pernyataan untuk mengukur variabel promosi yang diteliti pada marketplace Shopee.

Tabel 10. Hasil Pengujian Validitas Kemudahan Penggunaan Tokopedia

\begin{tabular}{|c|l|c|c|c|}
\hline No. & \multicolumn{1}{|c|}{ Pernyataan } & r Hitung & r Tabel & Keterangan \\
\hline 1. & $\begin{array}{l}\text { Pengunduhan dan } \\
\text { Pergistrasian }\end{array}$ & 0,855 & 0,161 & Valid \\
\hline 2. & $\begin{array}{l}\text { Fitur Mudah } \\
\text { Dipelajari }\end{array}$ & 0,880 & 0,161 & Valid \\
\hline 3. & Proses Pembelian & 0,897 & 0,161 & Valid \\
\hline 4. & $\begin{array}{l}\text { Metode } \\
\text { Pembayaran }\end{array}$ & 0,855 & 0,161 & Valid \\
\hline
\end{tabular}

Sumber: Data primer yang diolah, 2019

Berdasarkan tabel di atas menunjukkan seluruh instrumen valid untuk digunakan sebagai instrumen atau pernyataan untuk mengukur variabel kemudahan penggunaan yang diteliti pada marketplace Tokopedia.

Tabel 11. Hasil Pengujian Validitas Kemudahan Penggunaan Shopee

\begin{tabular}{|c|l|c|c|c|}
\hline No. & \multicolumn{1}{|c|}{ Pernyataan } & r Hitung & r Tabel & Keterangan \\
\hline 1. & $\begin{array}{l}\text { Pengunduhan dan } \\
\text { Pergistrasian }\end{array}$ & 0,819 & 0,161 & Valid \\
\hline 2. & $\begin{array}{l}\text { Fitur Mudah } \\
\text { Dipelajari }\end{array}$ & 0,883 & 0,161 & Valid \\
\hline 3. & Proses Pembelian & 0,912 & 0,161 & Valid \\
\hline 4. & $\begin{array}{l}\text { Metode } \\
\text { Pembayaran }\end{array}$ & 0,854 & 0,161 & Valid \\
\hline
\end{tabular}

Sumber: Data primer yang diolah, 2019

Berdasarkan tabel di atas menunjukkan seluruh instrumen valid untuk digunakan sebagai instrumen atau pernyataan untuk mengukur variabel kemudahan penggunaan yang diteliti pada marketplace Shopee.

\subsection{Uji Reliabilitas}

Uji reliabilitas merupakan kelanjutan dari uji validitas, uji reliabilitas digunakan untuk mengetahui keajegan atau konsistensi alat ukur yang biasanya menggunakan kuesioner. Dalam pengujian reliabilitas ini, peneliti menggunakan metode dengan cronbach alpha yang apabila hasil koefisien cronbach alpha lebih besar (>) dari taraf signifikansi $60 \%$ atau 0,6 maka kuesioner tersebut reliabel, dan apabila hasil koefisien cronbach alpha lebih kecil (<) dari taraf signifikansi $60 \%$ atau 0,6 maka kuesioner tersebut tidak reliabel. Menurut Sekaran dalam Priyatno (2014:64) reliabilitas kurang dari 0,6 adalah kurang baik, sedangkan 0,7 dapat diterima dan di atas 0,8 adalah baik.

Tabel 12. Hasil Uji Reliabilitas Tokopedia

\begin{tabular}{|l|c|c|c|}
\hline Variabel & $\begin{array}{c}\text { Cronbach's } \\
\text { Alpha }\end{array}$ & $\begin{array}{c}\text { N of } \\
\text { Items }\end{array}$ & Keterangan \\
\hline Produk & 0,836 & 3 & Baik \\
\hline Harga & 0,840 & 3 & Baik \\
\hline Promosi & 0,880 & 5 & Baik: \\
\hline $\begin{array}{l}\text { Kemudahan } \\
\text { Penggunaan }\end{array}$ & 0,894 & 4 & Baik \\
\hline
\end{tabular}

Sumber: Data primer yang diolah, 2019 
Hasil uji reliabilitas tersebut menunjukkan bahwa semua variabel dinyatakan reliabel karena telah melewati batas koefisien reliabilitas sehingga untuk selanjutnya item-item pada masing-masing konsep variabel tersebut layak digunakan sebagai alat ukur.

Tabel 13. Hasil Uji Reliabilitas Shopee

\begin{tabular}{|l|c|c|c|}
\hline Variabel & $\begin{array}{c}\text { Cronbach's } \\
\text { Alpha }\end{array}$ & $\begin{array}{c}\text { Nof } \\
\text { Items }\end{array}$ & Keterangan \\
\hline Produk & 0,781 & 3 & Dapat Diterima \\
\hline Harga & 0,835 & 3 & Baik \\
\hline Promosi & 0,818 & 5 & Baik \\
\hline $\begin{array}{l}\text { Kemudahan } \\
\text { Penggunaan }\end{array}$ & 0,886 & 4 & Baik \\
\hline
\end{tabular}

Sumber: Data primer yang diolah, 2019

Hasil uji reliabilitas tersebut menunjukkan bahwa semua variabel dinyatakan reliabel karena telah melewati batas koefisien reliabilitas sehingga untuk selanjutnya item-item pada masing-masing konsep variabel tersebut layak digunakan sebagai alat ukur.

\subsection{Uji Weighted Means Score (WMS)}

Setelah dilakukan uji Weighted Means Score (WMS) terhadap persepsi konsumen pada marketplace Tokopedia dan Shopee, dilakukan perbandingan diantara keduanya dengan hasil seperti dijelaskan pada tabel berikut:

Tabel 13. Perbandingan Hasil Uji Weighted Means Score Persepsi Konsumen pada Marketplace Tokopedia dan Shopee

\begin{tabular}{|l|c|c|}
\hline \multirow{2}{*}{ Variabel } & \multicolumn{2}{|c|}{ Hasil Uji WMS } \\
\cline { 2 - 3 } & Tokopedia & Shopee \\
\hline \multirow{2}{*}{ Produk } & 4,01 & 4,35 \\
\hline \multirow{3}{*}{ Harga } & (Sangat Baik) & (Sangat Baik) \\
\hline \multirow{2}{*}{ Promosi } & 3,98 & $\begin{array}{c}4,24 \text { (Sangat } \\
\text { Baik) }\end{array}$ \\
\cline { 2 - 2 } Kemudahan & (Sangat Baik) & \\
\hline Penggunaan & 4,07 & 4,38 (Sangat \\
\cline { 2 - 2 } & (Sangat Baik) & Baik) \\
\cline { 2 - 2 } Rata- rata & (Sangat Baik) & Baik) \\
\cline { 2 - 2 } & $16,27 / 4$ = 4,07 & $17,49 / 4=4,37$ \\
\cline { 2 - 2 } & (Sangat Baik) & (Sangat Baik) \\
\hline
\end{tabular}

Sumber: Data primer yang diolah, 2019

Dengan kesimpulan dari hasil perbandingan nilau uji WMS antara Tokopedia dan Shopee adalah sebagai berikut:

1. Pada variabel produk Shopee lebih diunggulkan dibanding Tokopedia, karena hasil uji WMS Shopee $(4,35)$ lebih besar dari Tokopedia $(4,01)$.

2. Pada variabel harga Shopee lebih diunggulkan dibanding Tokopedia, karena hasil uji WMS Shopee $(4,24)$ lebih besar dari Tokopedia $(3,98)$.

3. Pada variabel promosi Shopee lebih diunggulkan dibanding Tokopedia, karena hasil uji WMS Shopee $(4,38)$ lebih besar dari Tokopedia $(4,07)$.

4. Pada variabel kemudahan penggunaan Shopee lebih diunggulkan dibanding Tokopedia, karena hasil uji WMS Shopee $(4,42)$ lebih besar dari Tokopedia $(4,21)$.

\section{KESIMPULAN DAN SARAN}

\subsection{Kesimpulan}

Berdasarkan hasil penelitian dan pembahasan mengenai analisa persepsi konsumen terhadap marketplace Tokopedia dan Shopee kesimpulan sebagai berikut:

a. Pada variabel Produk (X1) Tokopedia didapat hasil rata-rata sebesar 4,01 dengan kriteria sangat baik. Sementara 
Shopee didapat hasil rata-rata 4,35 dengan kriteria sangat baik. Sehingga dapat diketahui persepsi konsumen pada dimensi produk, Shopee lebih unggul dari Tokopedia.

b. Pada variabel Harga (X2) Tokopedia didapat hasil rata-rata sebesar 3,98 dengan kriteria baik. Sementara Shopee didapat hasil rata-rata 4,24 dengan kriteria sangat baik. Sehingga dapat diketahui persepsi konsumen pada dimensi harga, Shopee lebih unggul dari Tokopedia.

c. Pada variabel Promosi (X3) Tokopedia didapat hasil rata-rata sebesar 4,07 dengan kriteria sangat baik. Sementara Shopee didapat hasil rata-rata 4,38 dengan kriteria sangat baik. Sehingga dapat diketahui persepsi konsumen pada dimensi promosi, Shopee lebih unggul dari Tokopedia.

d. Pada variabel Kemudahan Penggunaan (X4) Tokopedia didapat hasil rata-rata sebesar 4,21 dengan kriteria sangat baik. Sementara Shopee didapat hasil rata-rata 4,42 dengan kriteria sangat baik. Sehingga dapat diketahui persepsi konsumen pada dimensi kemudahan penggunaan, Shopee lebih unggul dari Tokopedia.

\subsection{Saran}

Beberapa saran dan pertimbangan yang disajikan berdasarkan penelitian ini antara lain:

1. Marketplace Shopee yang dipersepsikan konsumen lebih unggul dalam variabel produk (ketersediaan produk, keragaman produk, dan kualitas produk), variabel harga (keterjangkauan produk, kesesuaian harga dengan kualitas, dan kesesuaian harga dengan manfaat), variabel promosi (tampilan fitur, promo harga, iklan, event, dan Brand Ambassador), dan variabel kemudahan penggunaan (kemudahan pengunduhan dan peregistrasian, aplikasi mudah dipelajari dan digunakan, kemudahan proses pembelian, dan kemudahan metode pembayaran) agar selalu mempertahankan strategi produk, harga, promosi, maupun kemudahan penggunaan kepada pelanggan untuk menarik perhatian sekaligus mendapatkan loyalitas pelanggan. Dan untuk marketplace Tokopedia agar lebih berorientasi kepada Shopee dalam segi produk, harga, promosi, dan kemudahan penggunaannya, hal ini digunakan agar Tokopedia tidak kalah bersaing dengan Shopee dan tetap menjaga eksistensinya di pasar daring.

2. Untuk penelitian selanjutnya disarankan untuk bisa menambah variabel penelitian, lebih dikembangkan dalam cakupan marketplace lainnya, dan menggunakan jenis dan data penelitian yang berbeda seperti kualitatif, eksplanotori. Serta cakupan wilayah yang lebih luas, sehingga akan mendapatkan hasil data yang lebih lengkap.

\section{DAFTAR PUSTAKA}

Alma, B. 2018. Manajemen Pemasaran \& Pemasaran Jasa. Alfabeta. Bandung.

Ghozali, I. 2018. Aplikasi Analisis Multivariete Dengan Program IBM SPSS 23. Edisi Kedelapan. Badan Penerbit Universitas Diponegoro. Semarang.

Jogiyanto. 2007. Sistem Informasi Keperilakuan. Andi. Yogyakarta.

Kotler, P., dan Keller, K.L. 2009. Manajemen Pemasaran. Edisi Ketiga Belas. Erlangga. Jakarta.

Malau, H. 2017. Manajemen Pemasaran. Alfabeta. Bandung.

Peter, J.P., dan Olson, J.C. 2014. Perilaku Konsumen Dan Strategi Pemasaran. 
Edisi Kesembilan. Salemba Empat. Jakarta.

Priyatno, D. 2014. SPSS 22 Pengolahan

Data Terpraktis. Andi. Yogyakarta.

Sangadji, E.M., dan Sopiah. 2013. Perilaku

Konsumen Pendekatan Praktis. Andi.

Yogyakarta.

Sugiyono. 2003. Metode Penelitian Bisnis.

Edisi 1. Alfabeta. Bandung.

Sumarwan, Ujang. 2015. Perilaku

Konsumen. Edisi Kedua. Ghalia

Indonesia. Bogor.

Turban, E. dkk. 2018. Electronic

Commerce 2018 A Manajerial And

Social Network Perspective. Edisi

Kesembilan. Springer Nature.

Switzerland.

KBBI Daring. (c) 2016 Badan

Pengembangan Bahasa dan Perbukuan,

Kementerian Pendidikan dan

Kebudayaan Republik Indonesia.

https://kbbi.kemdikbud.go.id/ (18

September 2019).

$\begin{array}{lll}\text { Liputan } & 6 . & 2018 .\end{array}$

https://www.liputan6.com/tekno/read/3

230715/5-prediksi-tren-e-commerce-

di-indonesia-pada-2018 (15 September 2019).

Peta E-Commerce Indonesia. (C) 2018 iPrice Group Sdn Bhd (1113954 - D). All rights reserved. https://iprice.co.id/insights/mapofecom merce/ (2 Februari 2020).

PT Shopee. () Shopee 2019, https://careers.shopee.co.id/about/ (15 September 2019).

PT Tokopedia. (C) $2009 \quad-2019 \quad$ PT

Tokopedia,

https://www.tokopedia.com/about/. (15

September 2019). 